\title{
Helplessness in Chronic Obstructive Pulmonary Disease Patients: Assessment and Correlation with Sociodemographic Factors and Spirometry-based Severity
}

\author{
Akshee Batra, Garvit Chhabra, Pradeep Kumar Gupta ${ }^{1}$ \\ Department of Medicine, Maulana Azad Medical College, ${ }^{1}$ Department of Medicine, Deep Chand Bandhu Government Hospital, New Delhi, India
}

\section{Abstract}

Introduction: Mortality attributable to chronic obstructive pulmonary disease (COPD) in India is estimated to be among the highest in the world. Although identification and management of symptoms and signs of chronic lung diseases have improved, the psychosocial burden is often unrecognized and neglected. Psychological distress increases dependence on others, causes less effective self-management and longer hospital stays, and is known to greatly influence the disease progression. Aim: The aim of this study is to assess the degree of helplessness among COPD patients and establish its correlation with sociodemographic factors and disease severity. Subjects and Methods: This was a cross-sectional study carried out in a secondary care hospital of Delhi. A predesigned, pretested COPD Helplessness Index (CHI) questionnaire was administered to 224 participants aged 40 years or above, after obtaining informed consent. Global Initiative for Chronic Obstructive Lung Disease staging system for COPD was used to categorize patients according to their disease severity. The data were analyzed using the Statistical Package for the Social Sciences (SPSS) software version 17.0. Moreover, $P<0.05$ was considered significant. Results: CHI was found to be directly related with COPD severity $(P<0.001)$. Elderly patients, males, illiterates, and smokers were found to have a higher $\mathrm{CHI}$ score showing helplessness in study participants. Conclusions: There is a strong correlation between helplessness and pulmonary function with age, gender, literacy, and smoking status having a significant influence on the psychological state of COPD patients. An integrated effort on the part of the patients, doctors, and the society is required to reduce the burden of COPD.

Keywords: Chronic Obstructive Pulmonary Disease Helplessness Index, chronic obstructive pulmonary disease, helplessness, psychosocial

\section{INTRODUCTION}

The WHO defines chronic obstructive pulmonary disease (COPD) as a lung disease characterized by progressive and irreversible chronic obstruction of lung airflow that interferes with normal breathing. ${ }^{[1]}$ COPD is a major cause of morbidity and mortality across the globe responsible for $5 \%$ of all deaths in 2015. ${ }^{[1]}$ It is estimated that by 2030, COPD will become the third leading cause of death worldwide. ${ }^{[1]}$ Low- and middle-income countries such as India shoulder much of the burden with $90 \%$ of the total COPD-related deaths, where effective strategies for prevention and control are not always implemented or accessible. ${ }^{[1,2]}$

Despite this enormous health burden, COPD remains an under-researched disease in India with lack of awareness among patients regarding prevention and care. COPD involves a gradual and progressive decline in the lung

\begin{tabular}{|l|l|}
\hline \multicolumn{2}{|c|}{ Access this article online } \\
\hline Quick Response Code: & Website: \\
& www.ijrconline.org \\
\cline { 2 - 2 } & \\
\end{tabular}

function which results in increased dyspnea. The experience of breathlessness can be distressing and difficult to understand and control. A significant correlation has been established in the development of psychiatric comorbidities such as depression and anxiety in chronic diseases because of its impact on daily activities, sleep, and social life of patients. ${ }^{[3-6]}$ Although identification and management of the physical signs and symptoms of chronic lung diseases have improved, the psychosocial burden is often unrecognized and neglected. Maurer et al. suggested that the prevalence of psychological

Address for correspondence: Dr. Garvit Chhabra Room-136, Old Boys Hostel, Maulana Azad Medical College, New Delhi - 110 002, India. E-mail: garvit.chhabra26@gmail.com

This is an open access journal, and articles are distributed under the terms of the Creative Commons Attribution-NonCommercial-ShareAlike 4.0 License, which allows others to remix, tweak, and build upon the work non-commercially, as long as appropriate credit is given and the new creations are licensed under the identical terms

For reprints contact: reprints@medknow.com

How to cite this article: Batra A, Chhabra G, Gupta PK. Helplessness in chronic obstructive pulmonary disease patients: Assessment and correlation with sociodemographic factors and spirometry-based severity. Indian J Respir Care 2018;7:83-7. 
Batra, et al.: Helplessness in COPD

comorbidities is more in COPD compared to other chronic disorders. ${ }^{[7]}$

Psychological factors can create a vicious cycle by escalating breathlessness, physiological arousal, and panic. It has been shown that there is a strong correlation between psychological factors and reported levels of dyspnea in the advanced stages of COPD. ${ }^{[8]}$ The presence of psychological distress creates greater dependence on others, less effective self-management of respiratory symptoms, and longer hospital stays. Psychological factors may also be a risk factor for exacerbation of pulmonary disorders. ${ }^{[8]}$

COPD Helplessness Index (CHI) is a new tool to measure helplessness among patients with COPD and is associated concurrently with psychological health status, as developed and validated by Omachi et al. ${ }^{\left[{ }^{[9}\right.}$

Patient self-management is believed to be a key element of successful COPD treatment. ${ }^{[10]}$ However, self-management practices in COPD can be complex and burdensome. Psychological factors play a role in how well patients respond to attempts to improve self-management skills in COPD. Physical conditioning and social support have been shown to be associated with brief inpatient period and better rehabilitation in these patients. ${ }^{[11]}$ If patients are to live with chronic disease and maintain a good quality of life, it is imperative that these issues are not only recognized but also managed.

We, therefore, sought to assess, in a specific Indian context, helplessness in COPD patients and its correlation with disease severity and sociodemographic factors and design suitable management strategies. This will enable us to help patients cope better in their lifelong struggle with this debilitating disease.

\section{Subjects and Methods}

This was a cross-sectional observational study carried out over a period of 4 months (November 20, 2016-March 20, 2017). Two hundred and twenty-four clinically prediagnosed COPD patients attending the Chest Outpatient Department of Deep Chand Bandhu Government Hospital, New Delhi, during the study period were enrolled. An informed consent was obtained from every patient.

\section{Inclusion criteria}

Adult cases of clinically prediagnosed COPD with or without complications, aged 40 or above, were included in the study.

\section{Exclusion criteria}

Patients with comorbidities arising from causes other than COPD such as renal failure, hepatic failure, known psychiatric illness, and all types of diabetes were excluded from the study.

Data were collected using previous hospital/medical records after getting informed consent. A predesigned, pretested CHI questionnaire was then administered, and the responses were recorded.

\section{Baseline questionnaire}

This consisted of questions related to sociodemographic factors such as name, age, sex, occupation, religion, literacy, and smoking status.

\section{Chronic Obstructive Pulmonary Disease Helplessness Index questionnaire}

$\mathrm{CHI}$ is an internally consistent and valid measure, concurrently associated with health status and predictively associated with COPD exacerbation. The CHI questionnaire consists of 15 questions related to self-management of COPD. Each item was rated using a 0-4-point format by selecting one of the following response categories: "strongly agree," "agree," "neutral/neither agree nor disagree," "disagree," or "strongly disagree." In its final form, CHI has a score range of 0-60, with higher scores reflecting greater helplessness. ${ }^{[9]}$

\section{Pulmonary function test}

Spirometry was performed, and forced expiratory volume in the first second $\left(\mathrm{FEV}_{1}\right)$ was determined for each study participant. $\mathrm{FEV}_{1}$ (\% predicted), i.e., maximal amount of air one can forcefully exhale in $1 \mathrm{~s}$ was used to determine the severity of COPD.

\section{Data entry and analysis}

Severity of COPD was classified based on $\mathrm{FEV}_{1}$ (Global Initiative for Chronic Obstructive Lung Disease [GOLD], a validated system that classifies people with COPD based on their degree of airflow limitation) in four categories indicating severity of COPD (GOLD $1 \geq 80$; GOLD 2 = 50-79; GOLD $3=30-49$, and GOLD $4 \leq 30) .{ }^{[12]}$

The data were entered into the SPSS Inc. Released 2008. SPSS Statistics for Windows, Version 17.0. (Chicago, USA: SPSS Inc.) and summarized through frequency distributions. Suitable graphs were made to enhance visual appeal. Quantitative variables were summarized in terms of mean \pm standard deviation, and their correlations with qualitative variables were established using either ANOVA or unpaired $t$-test. $P<0.05$ was considered to be statistically significant.

\section{ResuLtS}

\section{General characteristics of the study population}

There were 176 males (78.6\%) and 48 females $(21.4 \%)$. A maximum number of COPD patients $(72,32.1 \%)$ were in the age group of $60-69$ years followed by those in $\geq 70$ years' age group $(54,24.1 \%)$. Figure 1 shows the age-wise and gender-wise distribution of patients.

The study population consisted of 132 Hindus $(58.93 \%)$ and 92 Muslims (41.07\%). Among the study participants, 154 COPD patients $(68.8 \%)$ were illiterate. About $75.9 \%$ of participants were present or past smokers with maximum being former smokers $(=96,42.9 \%)$ and maximum number of patients $(41.1 \%)$ belonged to GOLD Stage $3\left(\mathrm{FEV}_{1} \%\right.$ predicted $\left.=30 \%-49 \%\right)$ followed by Stage 4 $\left(\mathrm{FEV}_{1} \%\right.$ predicted $\left.<30 \%\right)$ with $28.6 \%$ of patients [Table 1 ]. 
The mean of CHI score for the study participants is $26.59 \pm 7.62$.

Table 1 shows correlation of CHI with sociodemographic factors and COPD severity. The CHI score was significantly higher among males than females $(23.33 \pm 7.35, P=0.001)$, among Hindus as compared to Muslims, in illiterates as compared to literates [Table 1]. CHI score was found to be highest among current smokers as compared to other categories. The difference in CHI score between the groups based on smoking status was found to be statistically significant $(P<0.001)$.

Increasing severity of COPD was linked to a higher $\mathrm{CHI}$ score showing helplessness with $P<0.001$. Age has a significant correlation with $\mathrm{FEV}_{1} \%$ predicted $(P<0.001)$ [Figure 2] as well as CHI score $(P=0.019)$ [Figure 2], i.e., if age is increasing, the value of $\mathrm{FEV}_{1} \%$ predicted will also decrease.

\begin{tabular}{|c|c|c|c|c|c|}
\hline Parameter & Category & $n$ & Mean \pm SD & Range & $P$ \\
\hline \multirow[t]{2}{*}{ Gender } & Male & 176 & $27.48 \pm 7.47$ & $11-45$ & \multirow[t]{2}{*}{0.001} \\
\hline & Female & 48 & $23.33 \pm 7.35$ & $13-37$ & \\
\hline \multirow[t]{2}{*}{ Religion } & Hindu & 132 & $27.47 \pm 7.74$ & $12-45$ & \multirow[t]{2}{*}{0.038} \\
\hline & Muslim & 92 & $25.33 \pm 7.3$ & $11-40$ & \\
\hline \multirow{3}{*}{$\begin{array}{l}\text { Smoking } \\
\text { status }\end{array}$} & Nonsmoker & 54 & $23.56 \pm 7.3$ & $11-40$ & \multirow[t]{3}{*}{$<0.001$} \\
\hline & Former smoker & 96 & $26.39 \pm 7.27$ & $12-45$ & \\
\hline & Current smoker & 74 & $29.07 \pm 7.53$ & $14-44$ & \\
\hline \multirow[t]{2}{*}{ Education } & Illiterate & 154 & $27.86 \pm 7.2$ & $12-45$ & \multirow[t]{2}{*}{$<0.001$} \\
\hline & Literate & 70 & $23.8 \pm 7.82$ & $11-37$ & \\
\hline \multirow{4}{*}{$\begin{array}{l}\text { GOLD } \\
\text { stages of } \\
\text { COPD } \\
\text { severity }\end{array}$} & 1. $\geq 80 \%$ & 8 & $12.25 \pm 1.17$ & $11-14$ & \multirow[t]{4}{*}{$<0.001$} \\
\hline & 2. $50 \%-79 \%$ & 60 & $19.23 \pm 3.61$ & $13-26$ & \\
\hline & 3. $30 \%-49 \%$ & 92 & $26.33 \pm 3.82$ & $17-33$ & \\
\hline & 4. $<30 \%$ & 64 & $35.66 \pm 3.28$ & $30-45$ & \\
\hline
\end{tabular}

COPD: Chronic obstructive pulmonary disease, GOLD: Global Initiative for Chronic Obstructive Lung Disease, SD: Standard deviation

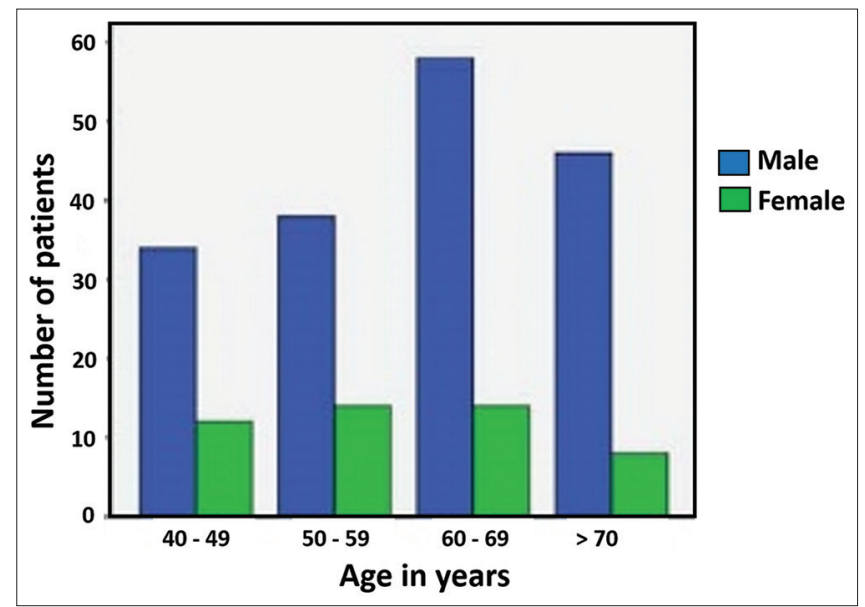

Figure 1: Age- and gender-wise distribution of the study participants
Similarly, with increase in age, the value of $\mathrm{CHI}$ will also increase. Furthermore, $\mathrm{FEV}_{1} \%$ is significantly correlated with CHI score $(P<0.001)$ i.e. $\mathrm{FEV}_{1}$ decreases with increase in CHI score [Figure 3].

\section{Discussion}

The present study examines correlation of helplessness in COPD patients with disease severity and sociodemographic factors by the use of CHI score. The mean $\mathrm{CHI}$ showed a consistent and statistically significant $(P<0.05)$ increase with rising severity (measured as per the GOLD guidelines). This can be attributed to increasing inability to work leading to low self-esteem, sense of worthlessness, financial burdens of the disease, poor mobility, social isolation, and loss of independence with rising severity. The inability to carry out daily living activities makes the patient very dependent on others. This is consistent with a study by van Manen et al. in 2002 according to which risk of depression in COPD patients was found to be 2.5 times greater for severe COPD when compared to patients in the control group. ${ }^{[13]}$

The mean $\mathrm{CHI}$ was found to be significantly higher among illiterate patients as compared to the literates. This can be attributed to the lack of awareness about the disease, treatment modalities, inability to comprehend and follow the guidelines, and lifestyle changes recommended by the physician, and hence, such individuals are more likely to be noncompliant. ${ }^{[14]}$ Such patients are likely to under-use maintenance therapy, and symptom-relieving drugs are often overused ${ }^{[14,15]}$ Studies in asthma and COPD have shown that adherence can be $<50 \%$ of prescribed medication. ${ }^{[14]}$

Analysis showed a relationship of $\mathrm{CHI}$ with age and higher age showing a higher CHI score. Problems of the elderly include dependence on family members for hospital visits and lack of support due to growing nature of nuclear families in urban India. In addition, due to cognitive impairment in elderly COPD patients, much of what is said in any medical consultation is forgotten soon after it ends. ${ }^{[16,17]}$

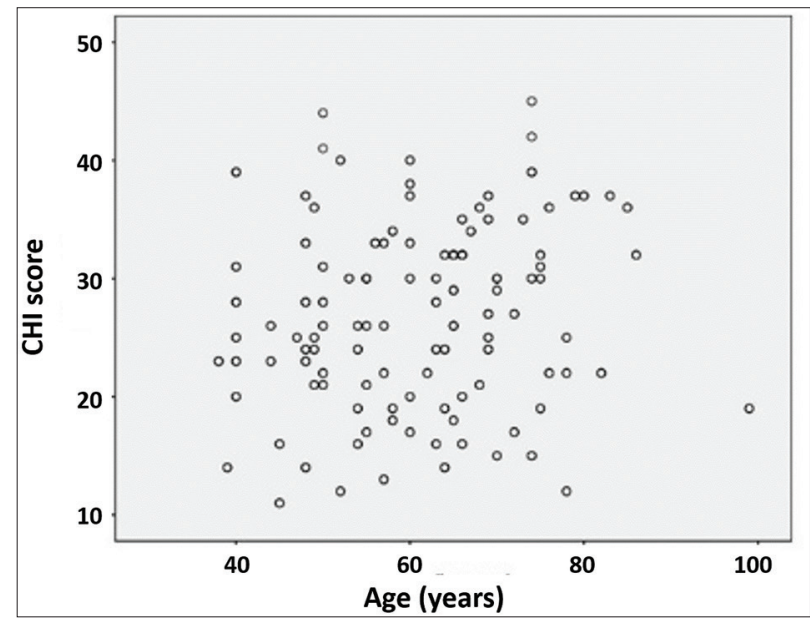

Figure 2: Correlation between age and Chronic Obstructive Pulmonary Disease Helplessness Index score 
Batra, et al.: Helplessness in COPD

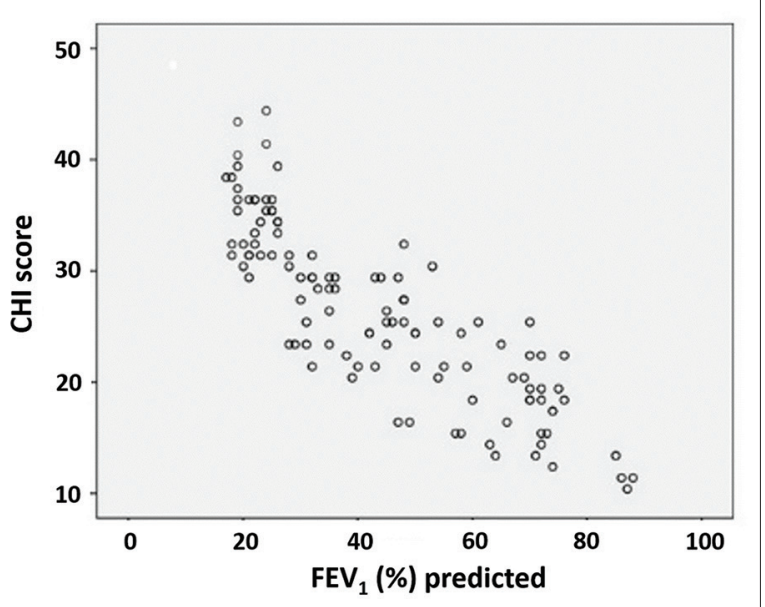

Figure 3: Correlation between volume in the first second (\%predicted) and Chronic Obstructive Pulmonary Disease Helplessness Index score

This result is in contrast to the findings of other studies in which young patients present greater levels of anxiety, and older patients report fewer emotional problems (depression, rage, and frustration) as they present less suffering in coping with the disease. ${ }^{[18-22]}$

A study revealed a significant correlation between mean CHI score and smoking status and the score being higher in former and current smokers than in nonsmokers. The risk of depression in COPD patients is twice as high among smokers as compared to nonsmokers, and the inability to quit is one of the major contributing factors for helplessness. ${ }^{[23-27]}$

The limitations of the study were a few: (1) other sociodemographic factors such as occupation and economic status which can also influence CHI were not assessed. (2) Since the study was done in nonrandomly selected government hospitals, selection bias might be present. (3) Hence, the findings cannot be a reflection of the general population. Only spirometry-derived $\mathrm{FEV}_{1}$ was considered to determine severity from the GOLD 2017's ABCD assessment tool. The assessment of symptoms/risks of exacerbation was not considered.

\section{Conclusions}

As concluded in the study, COPD progression is intricately linked with the development of helplessness, frustration, and hopelessness. The following measures should be taken to battle the psychological problem in COPD: (1) physicians should be alert of the psychological effects of chronic airway diseases, (2) the patients should be counseled regarding life-style changes, engagement in physical activity and seeking help from family should be stressed upon, (3) the management of psychological problems such as depression and anxiety in COPD patients must be included as a part of undergraduate education, (4) national program for chronic airway disorders must be revised to include standardized protocol associated mental health problems, (5) COPD patients should be educated about the management of the disease and symptoms such as depression and anxiety, and (6) family and peers must also be counseled to provide support to the patient. Alleviation of the helplessness associated with the disease requires an integrated effort on the part of the patients, doctors, and the community.

\section{Acknowledgment}

We would like to thank Dr. Suman Kumari, MS, Deep Chand Bandhu Government Hospital.

\section{Financial support and sponsorship}

Nil.

\section{Conflicts of interest}

There are no conflicts of interest.

\section{ReFERENCES}

1. WHO $\mid$ Chronic Obstructive Pulmonary Disease (COPD). World Health Organization; 2016. Available from: http://www.who.int/mediacentre/ factsheets/fs315/en/index.html. [Last accessed on $2017 \mathrm{Jul} 16$ ].

2. McKay AJ, Pa M, Patel RK, Majeed A. Management of chronic obstructive pulmonary disease in India: A systematic review. JRSM Short Rep 2012;3:85.

3. Kunik ME, Roundy K, Veazey C, Souchek J, Richardson P, Wray NP, et al. Surprisingly high prevalence of anxiety and depression in chronic breathing disorders. Chest 2005;127:1205-11.

4. Wagena EJ, Kant I, van Amelsvoort LG, Wouters EF, van Schayck CP, Swaen GM, et al. Risk of depression and anxiety in employees with chronic bronchitis: The modifying effect of cigarette smoking. Psychosom Med 2004;66:729-34.

5. Kunik ME, Braun U, Stanley MA, Wristers K, Molinari V, Stoebner D, et al. One session cognitive behavioural therapy for elderly patients with chronic obstructive pulmonary disease. Psychol Med 2001;31:717-23.

6. Mikkelsen RL, Middelboe T, Pisinger C, Stage KB. Anxiety and depression in patients with chronic obstructive pulmonary disease (COPD). A review. Nord J Psychiatry 2004;58:65-70.

7. Maurer J, Rebbapragada V, Borson S, Goldstein R, Kunik ME, Yohannes AM, et al. Anxiety and depression in COPD: Current understanding, unanswered questions, and research needs. Chest 2008;134:43S-56S.

8. Asnaashari AM, Talaei A, Haghigh B. Evaluation of psychological status in patients with asthma and COPD. Iran J Allergy Asthma Immunol 2012;11:65-71.

9. Omachi TA, Katz PP, Yelin EH, Iribarren C, Knight SJ, Blanc PD, et al. The COPD helplessness index: A new tool to measure factors affecting patient self-management. Chest 2010;137:823-30.

10. Bourbeau J, Nault D, Dang-Tan T. Self-management and behaviour modification in COPD. Patient Educ Couns 2004;52:271-7.

11. Alexopoulos GS, Sirey JA, Raue PJ, Kanellopoulos D, Clark TE, Novitch RS, et al. Outcomes of depressed patients undergoing inpatient pulmonary rehabilitation. Am J Geriatr Psychiatry 2006;14:466-75.

12. Vestbo J, Hurd SS, Agustí AG, Jones PW, Vogelmeier C, Anzueto A, et al. Global Strategy for the Diagnosis, Management, and Prevention of Chronic Obstructive Pulmonary Disease. Am J Respir Crit Care Med [Internet]. 2013;187:347-65.

13. van Manen JG, Bindels PJ, Dekker FW, IJzermans CJ, van der Zee JS, Schadé E, et al. Risk of depression in patients with chronic obstructive pulmonary disease and its determinants. Thorax 2002;57:412-6.

14. Rand CS. Patient adherence with COPD therapy. Eur Respir Rev 2005; 14:97-101.

15. Hand $\mathrm{CH}$, Bradley C. Health beliefs of adults with asthma: Toward an understanding of the difference between symptomatic and preventive use of inhaler treatment. J Asthma 1996;33:331-8.

16. Kessels RP. Patients' memory for medical information. J R Soc Med 2003;96:219-22. 
Batra, et al.: Helplessness in COPD

17. Allen SC, Ragab S. Ability to learn inhaler technique in relation to cognitive scores and tests of praxis in old age. Postgrad Med J 2002;78:37-9.

18. Clark TJ, Cochrane GM. Effect of personality on alveolar ventilation in patients with chronic airways obstruction. Br Med J 1970;1:273-5.

19. Dudley DL, Glaser EM, Jorgenson BN, Logan DL. Psychosocial concomitants to rehabilitation in chronic obstructive pulmonary disease. Part I. Psychosocial and psychological considerations. Chest 1980;77:413-20.

20. Dudley DL, Sitzman J, Rugg M. Psychiatric aspects of patients with chronic obstructive pulmonary disease. Adv Psychosom Med 1985; 14:64-77.

21. McCathie HC, Spence SH, Tate RL. Adjustment to chronic obstructive pulmonary disease: The importance of psychological factors. Eur Respir J 2002;19:47-53.
22. Prigatano GP, Wright EC, Levin D. Quality of life and its predictors in patients with mild hypoxemia and chronic obstructive pulmonary disease. Arch Intern Med 1984;144:1613-9.

23. Payne TJ, Stetson B, Stevens VM, Johnson CA, Penzien DB, Van Dorsten B, et al. The impact of cigarette smoking on headache activity in headache patients. Headache 1991;31:329-32.

24. Timmreck TC, Randolph JF. Smoking cessation: Clinical steps to improve compliance. Geriatrics 1993;48:63-6, 69-70.

25. Thornton A, Lee P, Fry J. Differences between smokers, ex-smokers, passive smokers and non-smokers. J Clin Epidemiol 1994;47:1143-62.

26. Parrott AC. Stress modulation over the day in cigarette smokers. Addiction 1995;90:233-44.

27. Rowe MG, Fleming MF, Barry KL, Manwell LB, Kropp S. Correlates of depression in primary care. J Fam Pract 1995;41:551-8. 